\title{
Does simultaneous lung-liver transplantation provide an immunologic advantage compared with isolated lung transplantation?
}

\author{
Jay K. Bhama, MD, ${ }^{a}$ Joseph M. Pilewski, MD, ${ }^{b}$ Diana Zaldonis, MPH, BSN, ${ }^{a}$ Paulo A. Fontes, MD, ${ }^{c}$ \\ Michael E. DeVera, MD, ${ }^{\mathrm{c}}$ Michael A. Shullo, PharmD, ${ }^{\mathrm{d}}$ Norihisa Shigemura, MD, PhD, ${ }^{\mathrm{a}}$ \\ Christian A. Bermudez, MD, ${ }^{\mathrm{a}}$ Yoshiya Toyoda, MD, PhD, ${ }^{\mathrm{a}}$ and Kenneth R. McCurry, MD, ${ }^{\mathrm{e}}$ Pittsburgh, Pa, \\ and Cleveland, Ohio
}

Simultaneous lung-liver transplantation (SLLT) is an uncommon procedure that is limited to patients unable to tolerate transplantation of either organ alone. It has been postulated that same-donor liver transplantation might provide an immunologic advantage to other simultaneously transplanted organs. We present our experience with SLLT comparing immunologic outcomes with those of patients receiving only lung transplantation to determine whether such a clinical benefit exists.

\section{CLINICAL SUMMARY}

Approval for retrospective review of our transplantation database was obtained from the University of Pittsburgh Medical Center Total Quality Control Council. Simultaneous lung-liver or heart-lung-liver transplantation was performed in 4 adults between 2003 and 2006. A control group was selected based on age, underlying diagnosis, date of transplantation, and immunosuppressive regimen.

All patients received induction therapy with rabbit antithymocyte globulin, alemtuzumab, or daclizumab. Our protocols for immunosuppression management, diagnosis/ treatment of acute rejection, and infection prophylaxis have been described previously. ${ }^{1}$

Fisher's exact test and an independent $t$ test were used for qualitative and quantitative variable analysis, respectively. Values are reported as means \pm standard deviations. Actuarial survival and freedom from rejection were calculated by using the Kaplan-Meier method $(P<.05$, log-rank test).

From the Department of Cardiothoracic Surgery, ${ }^{\mathrm{a}}$ the Department of Pulmonary, Allergy, and Critical Care Medicine, ${ }^{\mathrm{b}}$ and the Thomas E. Starzl Transplantation Institute $^{\mathrm{c}}$ and School of Pharmacy, ${ }^{\mathrm{d}}$ University of Pittsburgh Medical Center, Pittsburgh, Pa; and the Cleveland Clinic Heart and Vascular Institute, ${ }^{\mathrm{e}}$ Cleveland, Ohio.

Disclosures: Authors have nothing to disclose with regard to commercial support.

Received for publication March 24, 2010; revisions received Dec 31, 2010; accepted for publication Jan 24, 2011; available ahead of print Jan 24, 2011.

Address for reprints: Jay K. Bhama, MD, 200 Lothrop St, Suite C-900, Department of Cardiothoracic Surgery, University of Pittsburgh Medical Center, Pittsburgh, PA 15213 (E-mail: bhamajk@upmc.com).

J Thorac Cardiovasc Surg 2011;141:e36-8 0022-5223/ $\$ 36.00$

Copyright $@ 2011$ Published by Elsevier Inc. on behalf of The American Association for Thoracic Surgery

doi:10.1016/j.jtcvs.2011.01.056
TABLE 1. Demographics and perioperative data for the control and study groups

\begin{tabular}{|c|c|c|c|}
\hline Characteristic & $\begin{array}{c}\text { Control } \\
\text { group } \\
(\mathbf{n}=16) \\
\end{array}$ & $\begin{array}{l}\text { Study } \\
\text { group } \\
(n=4) \\
\end{array}$ & $\begin{array}{c}P \\
\text { value } \\
\end{array}$ \\
\hline \multicolumn{4}{|l|}{ Preoperative } \\
\hline Age (y) & $34.9 \pm 9.7$ & $30.7 \pm 4.9$ & .420 \\
\hline \multicolumn{4}{|l|}{ Sex } \\
\hline Male & $8(50 \%)$ & $3(75 \%)$ & .591 \\
\hline Female & $8(50 \%)$ & $1(25 \%)$ & .591 \\
\hline Weight $(\mathrm{kg})$ & $57.1 \pm 11.5$ & $56.7 \pm 3.6$ & .918 \\
\hline Height (in) & $65.1 \pm 3.7$ & $66.0 \pm 2.9$ & .641 \\
\hline Lung wait time (d) & $529 \pm 525$ & $363 \pm 428$ & .569 \\
\hline \multicolumn{4}{|l|}{ Diagnosis } \\
\hline $\mathrm{CF}$ & $12(75 \%)$ & $3(75 \%)$ & .751 \\
\hline $\mathrm{PPH}$ & $4(25 \%)$ & $1(25 \%)$ & .751 \\
\hline \multicolumn{4}{|l|}{ Operative } \\
\hline \multicolumn{4}{|l|}{ Lung ischemic time (min) } \\
\hline First lung & $284 \pm 68$ & $258 \pm 105$ & .541 \\
\hline Second lung & $381 \pm 91$ & $334 \pm 160$ & .432 \\
\hline CPB use & $8(50 \%)$ & $2(50 \%)$ & .708 \\
\hline \multicolumn{4}{|l|}{ Postoperative } \\
\hline \multicolumn{4}{|l|}{ Complications } \\
\hline Tracheostomy & $3(19 \%)$ & $3(75 \%)$ & .061 \\
\hline Bleeding & $1(6 \%)$ & $0(0 \%)$ & .800 \\
\hline Renal insufficiency & $4(25 \%)$ & $1(25 \%)$ & .751 \\
\hline Pneumonia & $5(31 \%)$ & $2(50 \%)$ & .439 \\
\hline \multicolumn{4}{|l|}{ LOS } \\
\hline ICU (d) & $20 \pm 40$ & $37 \pm 42$ & .458 \\
\hline Total (d) & $39 \pm 36$ & $65 \pm 43$ & .230 \\
\hline No. of TBB in first year & $6.5 \pm 2.6$ & $5.0 \pm 1.6$ & .283 \\
\hline $\begin{array}{l}\text { No. of ACR }>2 \\
\text { in first year }\end{array}$ & $11(69 \%)$ & $0(0 \%)$ & .026 \\
\hline BOS $\geq$ grade 1 & $3(19 \%)$ & $1(25 \%)$ & .837 \\
\hline \multicolumn{4}{|l|}{ Mean tacrolimus levels } \\
\hline $0-1 \mathrm{mo}$ & $12.0 \pm 1.4$ & $11.9 \pm 1.5$ & .849 \\
\hline $2-3 \mathrm{mo}$ & $13.6 \pm 1.8$ & $10.8 \pm 1.6$ & .012 \\
\hline $4-6 \mathrm{mo}$ & $12.8 \pm 2.4$ & $11.7 \pm 2.3$ & .435 \\
\hline $7-12 \mathrm{mo}$ & $12.1 \pm 2.9$ & $11.5 \pm 3.4$ & .774 \\
\hline $13-24 \mathrm{mo}$ & $12.5 \pm 1.9$ & $10.8 \pm 1.6$ & .115 \\
\hline $25-36 \mathrm{mo}$ & $10.7 \pm 2.4$ & $12.1 \pm 2.9$ & .337 \\
\hline
\end{tabular}

$C F$, Cystic fibrosis; $P P H$, primary pulmonary hypertension; $C P B$, cardiopulmonary bypass; $L O S$, length of stay, $I C U$, intensive care unit; $T B B$, transbronchial biopsy; $A C R$, acute cellular rejection; $B O S$, bronchiolitis obliterans syndrome. 

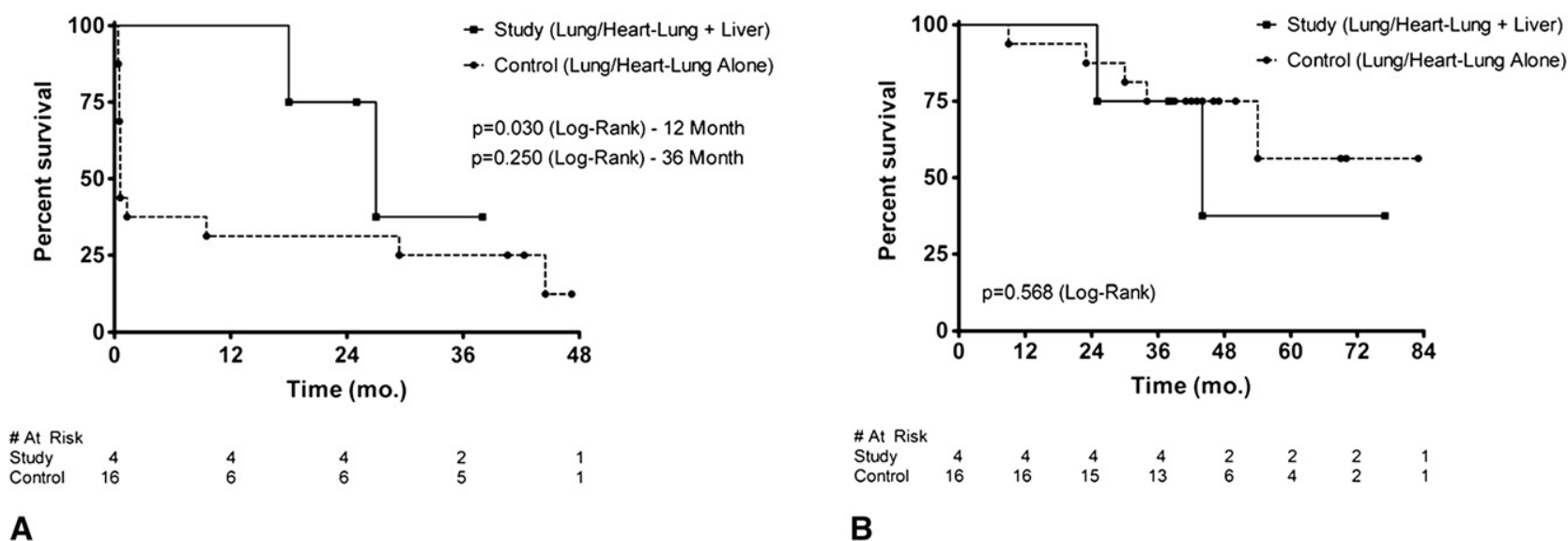

FIGURE 1. Kaplan-Meier survival plots comparing rejection-free survival (A) and patient survival (B) for the control and study groups.

Demographic and perioperative characteristics for the study and control groups are described in Table 1. The incidence of acute cellular rejection (grade $>2$ ) in the first year after transplantation was significantly higher in the control group compared with that seen in the study group $(68.8 \%$ vs $0 \%, P=.026)$. One patient in the study group had bronchiolitis obliterans syndrome at 18 months necessitating repeat double-lung transplantation after 2.3 years. Both groups had similar mean tacrolimus levels postoperatively, although the study group had significantly lower tacrolimus levels during months 1 to 3 . Rejection-free survival was better in the study group compared with the control group during the first year, but by the third year, there was no difference between the 2 groups (Figure 1, $A$ ). There were no operative mortalities in either group, and Kaplan-Meier survival estimates were similar (Figure 1, B).

\section{DISCUSSION}

Despite the encouraging results observed in recent years with lung transplantation, coexisting severe hepatic dysfunction remains a contraindication. The challenge associated with management of multiorgan disease coupled with the shortage of organs has led to a disinterest in SLLT. However, for some patients, this remains the only option for extending life and improving quality of life.

Previous experience with this tour de force of transplantation has been limited to small case series. ${ }^{2-4}$ The report by Faro and colleagues ${ }^{3}$ in 5 children with SLLT demonstrated lower rates of acute rejection and bronchiolitis obliterans syndrome compared with those seen in children receiving isolated lung transplantation. However, no study in adults has provided a similar comparison.

In our experience a potent early immunologic advantage was noted in patients who received SLLT compared with those undergoing isolated lung transplantation. This effect was noted despite both groups having similar tacrolimus levels. Interestingly, during months 2 to 3 after transplantation, lung-liver transplants were able to be maintained rejection free with significantly lower levels of tacrolimus compared with patients receiving isolated lung transplantation. Unfortunately, this effect was transient, and by the third year, there was no difference in the incidence of acute rejection between the groups.

Previous studies by Calne ${ }^{5}$ described the phenomenon of donor-specific immunologic protection provided by the liver. This has been attributed to numerous mechanisms, including the release of soluble histocompatibility antigens by the liver that are capable of inducing a state of tolerance and induction of microchimerism by passenger leukocytes within the liver. A similar immunologic privilege has been noted in multiorgan transplantation, including combined heart-kidney and heart-lung transplantation in which acute rejection of the heart has been lower than with isolated heart transplantation. This explanation exploits the potential for a large burden of foreign tissue to create a state of anergy within the recipient.

The clinical success noted in this and other studies augmented by a potential immunologic advantage creates an attractive option for patients with end-stage liver and lung disease. Unfortunately, our limited understanding of immunologic tolerance and the transient nature of this effect remain formidable obstacles. An additional obstacle is surviving to transplantation. Although no patients died while awaiting transplantation, other studies have reported waitlist mortalities. ${ }^{3}$

In conclusion, SLLT can be performed safely, with good early to midterm outcome. Same-donor liver transplantation might offer an immunologic advantage to simultaneously 
performed lung transplantation. Further clinical and experimental studies are warranted to better understand the potential benefits, as well as the mechanisms by which they are mediated.

\section{References}

1. McCurry KR, Iacono A, Zeevi A, et al. Early outcomes in human lung transplantation with thymoglobulin or campath- $1 \mathrm{H}$ for recipient pretreatment followed by posttransplant tacrolimus near-monotherapy. J Thorac Cardiovasc Surg. 2005;130:528-37.
2. Couetil JPA, Houssin DP, Soubrane O, et al. Combined lung and liver transplantation in patients with cystic fibrosis: a $4 \frac{1}{2} 2$ year experience. J Thorac Cardiovasc Surg. 1995; 110:1415-23.

3. Faro A, Shepherd R, Huddleston CB, et al. Lower incidence of bronchiolitis obliterans in pediatric liver-lung transplant recipients with cystic fibrosis. Transplantation. 2007;83:1435-9.

4. Grannas G, Neipp M, Hoeper MM, et al. Indications for and outcomes after combined lung and liver transplantation: a single-center experience on 13 consecutive cases. Transplantation. 2008;85:524-31.

5. Calne RY. Immunological tolerance-the liver effect. Immunol Rev. 2000;174: 280-2. 